\section{PEPTIC ULCER IN GLASGOW}

\section{A HOSPITAL SURVEY}

\author{
BY
}

\section{R. A. JAMIESON, F.R.C.S.Ed.}

\section{W. E. SMITH, M.A., M.B.}

AND

L. D. W. SCOTT, M.R.C.P.

(From the Peptic Ulcer Clinic, Glasgow Western Infirmary)

From an analysis of reports from hospitals in Great Britain Nicol (1941) suggested that there is a geographical variation in the relative frequency of gastric and duodenal ulcer. Doubtless other geographical variations would come to light if sufficient information were available. Unfortunately the majority of hospital reports deal exclusively with inpatients, and if the criteria for admission vary from one hospital to another the omission of out-patients may lead to serious error. So far the only complete survey of hospital patients with peptic ulcer in this country was made in the Greater London area (Avery Jones and Pollak, 1945). We present for comparison the experience of a hospital in the West of Scotland.

\section{Methods}

A survey was made of the out-patients and in-patients with peptic ulcer attending the Western Infirmary, Glasgow, during the two-year period from May 1, 1946, to April 30, 1948. For the purpose of the survey it was necessary to adopt an arbitrary standard of diagnosis. For out-patients the diagnosis was taken as established when an ulcer had been demonstrated radio'ogically, and for in-patients when ulcer was the final diagnosis made by the clinician in charge. Out-patients were interviewed daily immediately after they had been $x$-rayed ; the count of out-patients was complete as compared with the barium meal logbook, but, as was inevitable in a busy department, a fe.$v$ patients escaped interview. The count of in-patients was made by visiting each ward once a week, and virtually all the ulcer patients were interviewed save those who died within a few days of admission. The information obtained was recorded on punch cards to facilitate sorting. Care was taken to avoid counting any patient more than once, and (again to avoid duplication) out-patients subsequently admitted were classed as in-patients. Patients known to have a peptic ulcer but seeking advice for unrelated disease were excluded. Finally, to allow comparisons to be made with previous reports from other hospitals, we have wherever possible appended to our overall figures the data relating separately to outpatients and in-patients. This has proved all the more necessary as out-patients and in-patients differ (as we shall show) in respect of age, sex, site of ulcer, and complications.

\section{Number and Sex Ratio of Patients}

During the two-year period mentioned it was found that 3,258 ulcer patients passed through the hospital, comprising 2,286 out-patients and 972 in-patients. Figures for the total hospital attendances are not available for the exactly corresponding period, but during the two calendar years 1946 and 1947 the number of patients attending the general medical and surgical out-patient departments was 25,333 and the number of in-patients in the general medical and surgical wards was 22,425. Peptic ulcer accounted for a notable proportion of all hospital patients, especially in the out-patient service. To the 2,286 out-patients with ulcer must be added a further 244 out-patients who were subsequently admitted to the wards; peptic ulcer therefore accounted for some $10 \%$ of the total out-patients. Among. in-patients it accounted for $4.3 \%$.

There were 2,526 males and 732 females-a ratio of 3.5 . males to 1 female. This was considerably lower than the ratio of 4.7 to 1 given by Avery Jones and Pollak (1945) ; . it is a matter for regret that comparable estimates from. other hospitals have not been published. A point of interest. in our series, to which further reference will be made, was the different sex ratio in out-patients as compared with that of in-patients: in out-patients there were 3.1 males to 1 , female, and in in-patients 4.5 to 1 .

\section{Age and Site Distribution}

The age distribution of the ulcer patients attending hos- . pital is shown in Fig. 1. The large number of patients PEPTIC ULCER WESTERN INFIRMARY 1945-48 AGE INCIDENCE. $\square$ MALE: $\square$ FEMALE
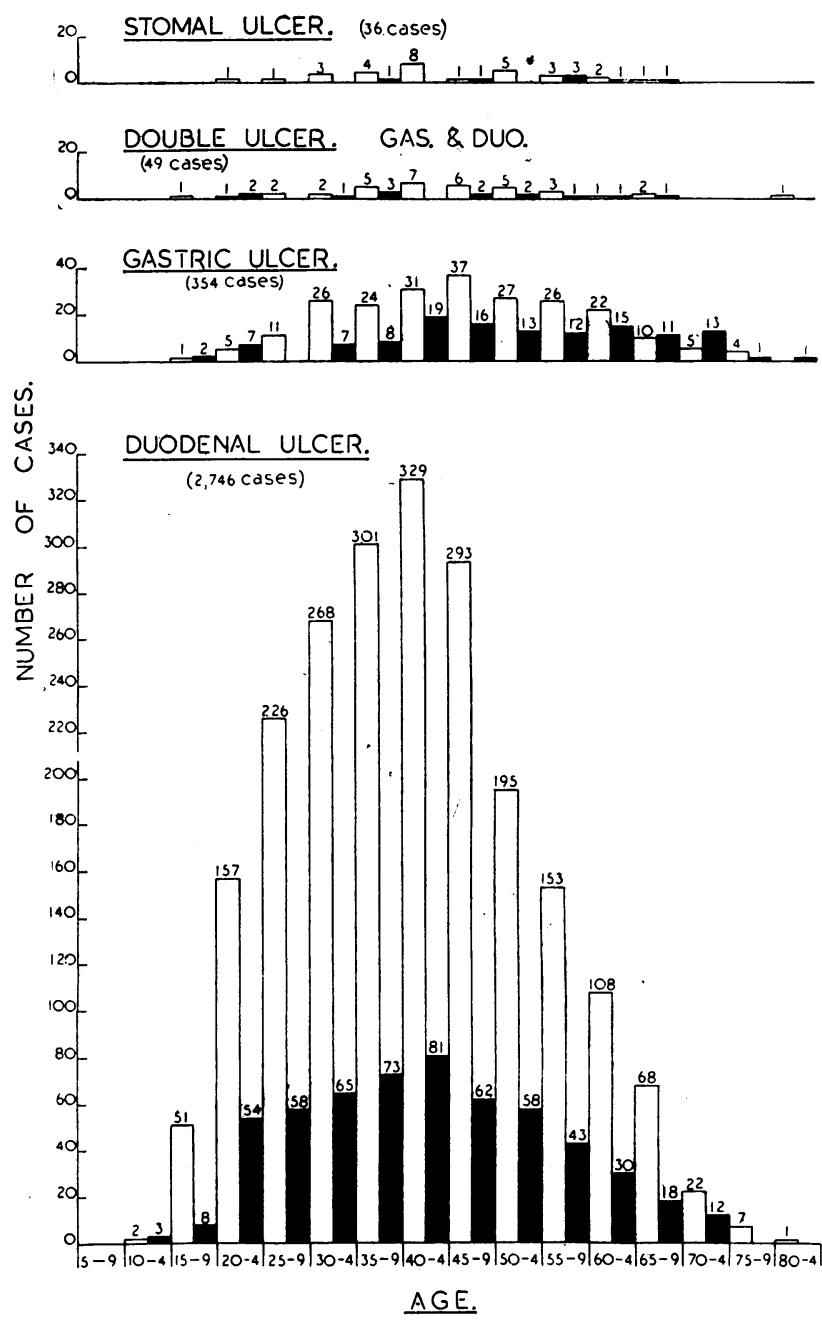

FIG. 1.-Peptic ulcer: Age and sex incidence. In 52 cases the ulcer site was not stated and in 4 cases of gastric and 17 of duodenal ulcer the patient's age was omitted.

(some $60 \%$ ) concentrated between the ages of 30 and 50 is worthy of notice. This emphasizes again the economic importance of peptic ulcer as a cause of chronic ill-health at a time of life when its victims are at the height of their wage-earning capacity.

The great preponderance of duodenal over gastric ulcer is also well shown in Fig. 1, and the overall ratio was 2,763 duodenal ulcers to 358 gastric ulcers, or 7.7. to 1 . The preponderance was greater in males than in females-in 
males it was 9.5 to 1 , whereas in females it was only 4.4 to 1. The ratio differed also in out-patients as compared with in-patients.*

An observation of great interest was the striking difference in the ages of patients with duodenal ulcer as compared with those with gastric ulcer. Thus in males the mean age for duodenal ulcer was 41.8 years and for gastric ulcer it was 47.6. In females the difference was even greater-namely, 42.0 and 51.5 years respectively. These large variations seem to reflect a real age difference in the incidence of duodenal and gastric ulcer. Strong support for this inference is provided by the evidence presented in Fig. 2 and Table I, in which duodenal and gastric ulcers

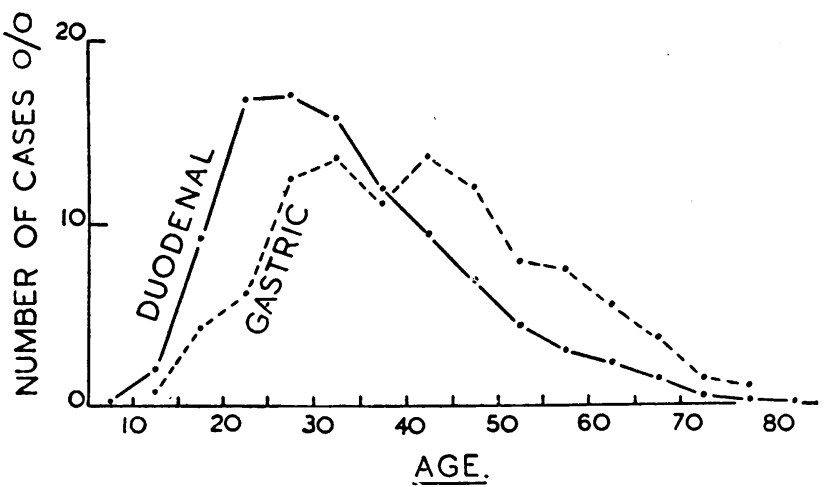

FIG. 2.--Peptic ulcer: Age at onset of symptoms.

TABLE I.-Age at Onset of Symptoms

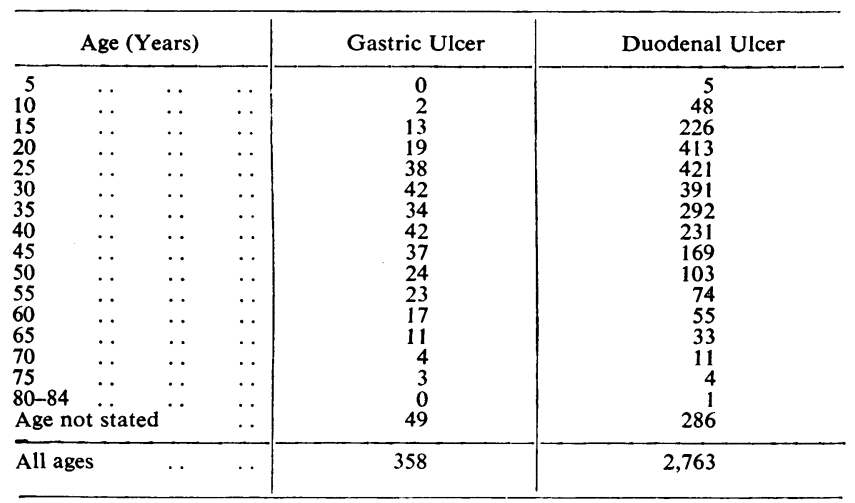

are contrasted in respect of the age at onset of symptoms. It will be seen that symptoms begin at an earlier age in duodenal ulcer than in gastric ulcer.

\section{Complications of Peptic Ulcer}

Of the total 3,258 patients dealt with during the survey, $1,237(38 \%)$ were undergoing treatment for a complication of peptic ulcer or had suffered a complication at some time in the past. Of the common complications we have classified perforation and haemorrhage, but have not felt justified in attempting to classify stenosis. Patients requiring operation for advanced stenosis have been classed with patients requiring operation for other intractable disability under the general term "elective operation." The incidence of complications (past or present) is shown in Table II.

It will be noted that the complication rate was much higher among in-patients than among out-patients. It is indeed hardly a matter for surprise that in-patients should

*The actual D.U./G.U. ratios were in males $1,559 / 137$ for outpatients as against $638 / 94$ for in-patients; and in females 454 /86 for out-patients as against $112 / 41$ for in-patients. Excluded from the calculation of duodenal-ulcer/gastric-ulcer ratios were 36 patients with stomal ulcer, 49 with combined gastric and duodenal ulcer, and 52 in whom the site was not stated.
TABLE II.-Incidence of Complications

\begin{tabular}{|c|c|c|c|c|c|}
\hline & \multicolumn{2}{|c|}{ Out-patients } & \multicolumn{2}{|c|}{ In-patients } & \multirow{2}{*}{ Total } \\
\hline & Male & Female & Male & Female & \\
\hline 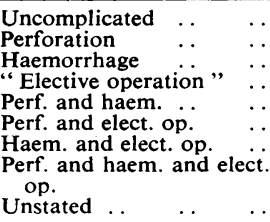 & $\begin{array}{r}1,208 \\
115 \\
170 \\
33 \\
25 \\
7 \\
14 \\
9 \\
149\end{array}$ & $\begin{array}{r}414 \\
3 \\
71 \\
14 \\
1 \\
-5 \\
-\end{array}$ & $\begin{array}{r}159 \\
225 \\
145 \\
85 \\
36 \\
53 \\
63 \\
29 \\
1\end{array}$ & $\begin{array}{r}42 \\
17 \\
56 \\
30 \\
5 \\
1 \\
20 \\
5\end{array}$ & $\begin{array}{r}1,823 \\
360 \\
442 \\
162 \\
67 \\
61 \\
102 \\
43 \\
\\
198\end{array}$ \\
\hline Totals & 1,730 & 556 & $796^{\circ}$ & 176 & 3.258 \\
\hline
\end{tabular}

comprise chiefly those who have suffered some complication of their ulcers. However, when it is shown that only one out of five of the out-patients suffered a complication as against four out of five of the in-patients, it becomes clear that out-patients and in-patients represent different sections of the ulcer community. We believe that it is because in-patients are selected mainly on the basis of past or present complications that they differ from out-patients in so many respects; the outstanding differences in age, sex, and site of ulcer have been stressed throughout this report.

The commonest complications were perforation and haemorrhage ; the relative frequency of these is shown in Table III. In gastric ulcer haemorrhage was commoner

TABLE III.-Relative Frequency of Perforation and Haemorrhage

\begin{tabular}{|c|c|c|c|c|}
\hline \multirow[b]{2}{*}{$\begin{array}{l}\text { Gastric ulcer } \\
\text { Duodenal ulcer .. }\end{array}$} & \multicolumn{2}{|c|}{ Perforation } & \multicolumn{2}{|c|}{ Haemorrhage } \\
\hline & $\begin{array}{l}28 \text { males } \\
456, "\end{array}$ & $\begin{array}{c}9 \text { females } \\
23 \stackrel{,}{,}\end{array}$ & $\begin{array}{l}51 \text { males } \\
294 \Leftrightarrow,\end{array}$ & $\begin{array}{l}30 \text { females } \\
114 \text {, }\end{array}$ \\
\hline
\end{tabular}

than perforation in both sexes. In duodenal ulcer, however, there was a conspicuous sex difference: in males perforation exceeded haemorrhage in the ratio of 456 to 294 , or 1.5 to 1 , whereas in females perforation fell short of haemorrhage in the ratio of 23 to 114 , or 1 to 5 . This remarkable sex difference in duodenal ulcer remains unexplained. If it be accepted that duodenal ulcers which perforate are situated anteriorly, whereas those which bleed are mainly posterior, it would seem that women must have a relative immunity from ulcer of the anterior duodenal wall. This interesting speculation merits further investigation.

\section{Site of Ulcer and Social Status}

It has been claimed (Morris and Titmuss, 1944) that among the poorer classes there is a disproportionately large number of deaths due to gastric ulcer as compared with duodenal ulcer. It was of interest, therefore, to arrange our patients according to social status and site of ulcer, but it can be said at once that we were unable to confirm this finding. For the social grading we have used the scheme of the Registrar-General for England and Wales (1931) ; Grade I includes the professions, Grade III skilled artisans, Grade V unskilled workers, and Grades II and IV are intermediate.

Table IV shows that the observed and expected numbers were in general in close agreement. There was no systematic surplus of gastric ulcers in Grade V, and indeed in two of the three age groups there was actually a small deficit.

Lastly, we examined the possibility that peptic ulcer in women might be commoner in the unmarried because they tend to have the same conditions of work and meal-times as men. Among 584 women between the ages of 20 and 64 the unmarried amounted to $150(26 \%)$. This seemed to us to be a high proportion, and we were surprised to discover 
Table IV.-Social Grade of Male Patients Aged 20-64

\begin{tabular}{|c|c|c|c|c|c|}
\hline \multirow{2}{*}{ Age } & \multirow{2}{*}{ Site } & \multicolumn{4}{|c|}{ Social Grade } \\
\hline & & I and II & III & IV & V \\
\hline $20-34$ & $\begin{array}{l}\text { Gastric } \\
\text { Duodenal }\end{array}$ & $4_{46}^{2(2 \cdot 9)}$ & $416(26 \cdot 0)$ & $90^{7(5 \cdot 8)}$ & ${ }_{78}^{11(5 \cdot 3)}$ \\
\hline $35--49$ & $\begin{array}{l}\text { Gastric } \\
\text { Duodenal }\end{array}$ & $65^{3(6 \cdot 2)}$ & $\begin{array}{r}62(58 \cdot 8) \\
589\end{array}$ & $\begin{array}{r}13(11 \cdot 9) \\
119\end{array}$ & $123(12 \cdot 1)$ \\
\hline $50-64$ & $\begin{array}{l}\text { Gastric } \\
\text { Duodenal }\end{array}$ & $40^{6(6 \cdot 5)}$ & $\begin{array}{c}40(42 \cdot 8) \\
266\end{array}$ & $\begin{array}{l}15(9 \cdot 8) \\
55\end{array}$ & $\begin{array}{r}8(9 \cdot 9) \\
63\end{array}$ \\
\hline
\end{tabular}

From the table are excluded 80 duodenal ulcer and 11 gastric ulcer patients whose social grade was not stated duodenal ulcer and 11 gastric ulcer patients gastric ulcers expected at each age if site and social grade were independent.

that it agreed fairly closely with the proportion of unmarried women in the general population; for women aged 20-64 the 1931 Census for England and Wales gives the proportion of unmarried as $3,747,699$ to $11,743,965$, or $32 \%$.

\section{Relative Incidence of Duodenal and Gastric Ulcer in Great Britain}

Nicol (1941) stated that the relative incidence of duodenal and gastric ulcers varied throughout Great Britain, and ranged from 8 to 1 in Scotland to 1 to 1 in London. $\mathrm{He}$ doubted whether the London figures were truly representative of the ulcer population in that area, and suggested that it was the practice in London to treat more cases of duodenal ulcer as out-patients than was usual in other cities, so producing an artificial difference in the ratio of duodenal to gastric ulcers. This was confirmed by Avery Jones and Pollak (1945), who by including out-patients found that in London duodenal ulcer was two and a half times as common as gastric ulcer. Nevertheless there is still a gross discrepancy with our finding in the West of Scotland that duodenal ulcer is about eight times as common as gastric ulcer.

Figures are not available giving the relative incidence of duodenal and gastric ulcers in the general population, but during the war many reports were made on peptic ulcer in the Services, and in these the D.U./G.U. ratio varied from 4.0 to 1 (Rook, 1943) to 8.7 to 1 (Morris, 1940). By taking only males under 45 years, and so making their series comparable with the Service patients, Avery Jones and Pollak made the ratio of duodenal to gastric ulcer 5.5 to 1 . It would therefore appear that their experience with this age group may be taken as representative. However, when the same group of patients is considered in our series the D.U./G.U. ratio becomes 13.2 to 1 . Consequently it must be concluded that the relative preponderance of duodenal ulcer over gastric ulcer is much greater in hospital practice in Scotland than in London. Whether this difference is due to an absolute increase in duodenal ulcer or a deficiency of gastric ulcers remains to be established.

\section{Summary}

A two-year survey of the peptic ulcer patients attending a Glasgow hospital is reported. The survey included both inpatients and out-patients. The chief findings were:

1. The overall sex ratio was 3.5 males to 1 female.

2. The overall site ratio was 7.7 duodenal ulcers to 1 gastric (9.5 to 1 for males and 4.4 to 1 for females). There was no evidence that the ratio of duodenal to gastric ulcer was influenced in males by social status or in females by marital status.

3. Patients with duodenal ulcer were notably younger than patients with gastric ulcer, and the age at onset of symptoms was also lower in duodenal ulcer.

4. The complications of ulcer which the patients had suffered were recorded. Attention is drawn to the relative rarity of perforation in duodenal ulcer in women.

5. In-patients differed from out-patients in respect of sex age, site of ulcer, and complications. This is attributed to the fact that in-patients were a selected group comprising chiefly patients who had suffered one or more complications.

6. The ratio of duodenal to gastric ulcer appears to be much higher in Scotland than in London. This finding is discussed.

We wish to express our gratitude to Professor Illingworth, who proposed this survey, to the physicians, surgeons, and radiologists of the Western Infirmary for their ready co-operation, and to Miss S. G. Murray, Miss C. M. Atkinson, and Miss M. K. Chisholm for much secretarial help, loyally and efficiently given.

\section{REFERENCES}

Jones, F. A., and Pollak, H. (1945). British Medical Journal, 1, 797.

Morris, H. (1940). Ibid., 2, 235:

Morris, J. N., and Titmuss, R. M. (1944). Lancet, 2, 841.

Nicol, B. M.'(1941). British Medical Journal, 2, 780.

Rook, A. F. (1943). Lancet, 1, 733 .

\section{THE DIET, HAEMOGLOBIN VALUES, AND BLOOD PRESSURES OF OLYMPIC ATHLETES}

\author{
BY
}

\author{
W. T. C. BERRY, M.A., M.B. \\ J. B. BEVERIDGE \\ E. R. BRANSBY, Ph.D. A. K. CHALMERS, B.Sc. \\ B. M. NEEDHAM, B.Sc. H. E. MAGEE, M.B., D.Sc. \\ H. S. TOWNSEND, M.B. \\ Ministry of Health
}

AND

C. G. DAUBNEY, M.Sc., F.R.I.C.

Department of the Government Chemist

At a recent meeting of the Nutrition Society on the nutrition of athletes it was made clear that there were but few scientific data relating to the nutrition and physiology of athletes. The gathering of many athletes in London for the Olympic Games gave an opportunity for the study of certain aspects of their physiologynamely, the food consumption, haemoglobin levels, and blood pressures.

\section{Food Consumption}

Most of the athletes were housed and fed at the R.A.F. camp at Uxbridge, others being accommodated at a number of smaller centres. Different nationalities occupied different blocks, a dining-room in each block being reserved for the athletes. Food was prepared in three separate kitchens at the main camp. There was also one central cafeteria for snacks and light meals where athletes could entertain their guests. If any athletes were unable to come to camp for a meal they were provided with sandwiches; occasionally they had meals in outside restaurants. These various arrangements made the collection of food records somewhat complicated. Many of the athletes were under considerable mental tension before their contests, and it was therefore essential to exercise a good deal of tact in obtaining the food data. A further complication was that national dishes were in many cases provided and the nutrient values of these were not available in the customary tables of food composition.

The method of survey was as follows. On the Monday of each week the athletes chosen for study were interviewed and their co-operation enlisted. The study of each athlete lasted from Tuesday (breakfast) until Friday (supper)-that is, for four days. The athletes collected their food on the cafeteria system; a dietitian followed and was served with duplicates of the meal. At the end 